\title{
The Perceived Role of the Strength and Conditioning Coach in Athlete Rehabilitation
}

\author{
Andrew S. L. Armstrong BPhty \\ Institute of Sport, Exercise \& Health, Otago Polytechnic, Dunedin, New Zealand
}

Codi A. Ramsey PhD

Institute of Sport, Exercise \& Health, Otago Polytechnic, Dunedin, New Zealand

Simon Body MProfPrac(Dist)

Institute of Sport, Exercise \& Health, Otago Polytechnic, Dunedin, New Zealand

\section{ABSTRACT}

Strength and conditioning $(S \& C)$ coaches may collaborate with physiotherapists in athlete rehabilitation, but their role has not been documented. Therefore, this study aimed to clarify their role through the perspectives of physiotherapists and S\&C coaches. The researchers conducted semi-structured interviews in New Zealand with four physiotherapists and five S\&C coaches, including one who had previously been a physiotherapist. Thematic analysis identified 13 themes analysed in four categories: current role (teamwork with the rehabilitation team, level of involvement, and physical roles), proposed role (teamwork with the rehabilitation team, level of involvement, and physical roles), variables (rehabilitation team structure, governance, relationships in the rehabilitation team, and the athlete), and significance (positive and negative). Currently, most S\&C coaches have a small role in providing performance training at the end of rehabilitation. Participants thought they should be involved earlier, but poor communication and collaboration with health professionals reduce their role. They proposed that S\&C coaches should be somewhat involved following a health professional's diagnosis, increasing their involvement as athlete function improves and the physiotherapist's role decreases. Participants agreed that this role should be flexible and account for each clinical context.

Armstrong, A. S. L., Ramsey, C. A., \& Body, S. (2021). The perceived role of the strength and conditioning coach in athlete rehabilitation. New Zealand Journal of Physiotherapy, 49(2), 89-98. https://doi.org/10.15619/NZJP/49.2.05

Key Words: Professional Role, Physical Conditioning, Human, Physiotherapy, Return to Sport, Sports Medicine

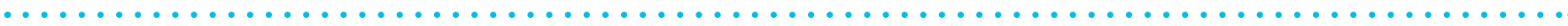

\section{INTRODUCTION}

Despite their roles in injury prevention and health promotion, strength and conditioning (S\&C) coaches are traditionally thought of as performance professionals, not health professionals (Triplett et al., 2017). S\&C coaches generally work with healthy athletes to prepare them for the physical demands of their sport. They incorporate specific exercises into their training programmes to minimise the risk of injury (prehabilitation; Meir et al., 2007). If an athlete is injured, health professionals such as physiotherapists will rehabilitate them.

Physiotherapists can help athletes rehabilitate in medical terms (i.e., range of motion, pain, inflammation, neuromuscular control, muscle, and tissue strength; Bulley et al., 2005; Kraemer et al., 2009; Physiotherapy Board of New Zealand, 2018). Still, those without sport-specific or S\&C knowledge will struggle to rehabilitate athletes in performance terms (sportspecific strength, power, agility, endurance, and coordination). Therefore, many athletes do not rehabilitate to their preinjury level of function. S\&C coaches may help injured athletes return to their previous level of performance and reduce the risk of reinjury (Bedoya et al., 2015; Sommerfield et al., 2020; Wong et al., 2010).

In some elite sport settings, S\&C coaches collaborate with physiotherapists in an athlete's rehabilitation to smoothly integrate the athlete back into sport. Still, the role of these $S \& C$ coaches is not well documented. If health professionals and athletes are unaware of this role, S\&C coaches cannot help rehabilitating athletes. Kraemer et al. (2009) has suggested a framework for this role in the United States. They indicate that $S \& C$ coaches be involved in the end stages of rehabilitation and performance training before returning to sport. Others have advised how to integrate S\&C principles (e.g., periodisation, maximal strength training, power training, and sport-specific training) into rehabilitation (Lorenz et al., 2010; Maestroni et al., 2020; Reiman \& Lorenz, 2011). However, no studies have explored whether $S \& C$ coaches perform these roles in practice.

Defining S\&C coaches' roles in athlete rehabilitation may improve their involvement in rehabilitation teams. Role clarity can enhance trust among health professionals, leading to improved support and value of each other's roles and communication (Sims et al., 2015). Therefore, the aim of this study was to explore the perspectives of physiotherapists and $S \& C$ coaches in New Zealand on the role of S\&C coaches in athlete rehabilitation.

\section{METHODS}

This qualitative study used individual semi-structured interviews (Holloway \& Galvin, 2016) to identify S\&C coach and physiotherapist perceptions of the role of S\&C coaches in athlete rehabilitation. The 32-item Consolidated criteria for Reporting Qualitative research (COREQ) checklist was used to report this study (Tong et al., 2007). Ethical approval was obtained from 
the Otago Polytechnic Research Ethics Committee (reference number 840).

The primary author (AA) conducted all interviews with the physiotherapists and S\&C coaches and independently transcribed and coded each interview. The other researchers provided quality checking of the writing, methodology, and thematic analysis in this study. The primary author had a professional relationship with two of the physiotherapists and one S\&C coach before the commencement of this study. The primary researcher informed participants about his background and current study aims before beginning the interviews with the clinicians.

\section{Study design}

A six-step inductive approach outlined by Braun and Clarke (2006) guided the analysis of this study. This approach allowed for flexible yet recursive analysis of the data to develop themes that accurately portray the participants' insights (Braun \& Clarke, 2006, 2013).

\section{Participants}

Participants were selected from a sampling survey completed by physiotherapists and S\&C coaches in New Zealand. The survey was spread using chain referral (snowball) sampling (Mack et al., 2005). This technique aimed to maximise the study population, find participants that may not be easily accessible to researchers, and improve the external validity of the findings.

The sampling survey included participants if they were: a resident or citizen of New Zealand or Australia; registered as a physiotherapist with the Physiotherapy Board of New Zealand and held a current annual practising certificate, or were registered and had an annual practising certificate at the time of athlete interaction; an S\&C coach as defined in the National Strength and Conditioning Association Strength and Conditioning Professional Standards and Guidelines (Triplett et al., 2017); of legal age to consent (Medical Council of New Zealand, 2019); and worked with an 'athlete' (who meets adapted criteria proposed by Araújo and Scharhag (2016) to include community sports athletes) within their care as a physiotherapist or S\&C coach who had been 'moderately disabled' by an injury based on a score of 2 or higher on 'the Bull five-point scale of disability' (Bull, 1978).

The sampling survey excluded participants if they: were unable to provide informed consent; did not speak fluent English, or their speech was impaired such that interview data could not be obtained, and they were unable to provide an interpreter; could not attend an interview and did not have access to adequate software for online interviewing; or had an acute or chronic condition that would limit the ability to participate in the study.

The data gathered from the sampling survey were not included in the thematic analysis. However, it helped provide talking points for the interviews and demographic information, including age, sex, qualifications, and experience in their field and athlete rehabilitation. This information allowed for subgroup analysis if themes and categories were consistent among participants with similar demographics.

Two physiotherapists who were also S\&C coaches, 47 physiotherapists, and 19 S\&C coaches completed the survey.
Of the 68 people who completed the sampling survey, 37 consented to be interviewed. Purposive sampling was used to recruit interviewees from the pool of volunteers (Battaglia, 2008; Onwuegbuzie \& Leech, 2007).

One S\&C coach with a background as a physiotherapist, four physiotherapists, and four S\&C coaches across New Zealand were interviewed using a web-based video platform (Zoom Video Communications Inc., San Jose, California). Audio and video were recorded for each interview and stored in a secure file. All interviews were between 60 and 95 min and no interview was repeated. Written and verbal informed consent was gained before starting the interviews.

Data collection

The primary author (AA) interviewed all participants using a single set of semi-structured, open-ended questions (Appendix A). These questions developed over several weeks through discussion with all researchers with two pilot interviews completed before the first interview. These interviews helped to identify key questions that should be addressed and refine the interview skills of the primary author. The questions in the interviews aimed to address the research question: "what is the role of S\&C coaches in athlete rehabilitation?" by addressing four topics:

- current role

- proposed role

- variables that affect the role

- significance of the role

The interview questions addressed ideas surrounding these secondary research questions, but they were not directly asked in the interviews. The interview questions were adapted during the interview to increase the depth and vitality of the interview data. The final analysis was completed from the interview data alone. Audio recordings from the interviews were transcribed verbatim by the primary author.

Data analysis

The primary author conducted and transcribed the interviews and read all the transcripts multiple times to ensure familiarity with the data. A data-driven approach to coding was taken for the transcripts (Braun \& Clarke, 2013). Codes were assigned to text segments to accurately portray what participants communicated in the interview. The primary author categorised the codes into four groups relating to the research topics: current role, proposed role, variables, or significance. Within each of these groups, the codes were recorded in a Microsoft Excel (2016) spreadsheet and categorised into subthemes, then candidate themes.

The candidate themes were reviewed at the level of the codes and data to ensure they accurately reflected the interview content. Cross-checking and discussion between the researchers helped confirm these themes. All participants were sent a summary of the results and asked to comment to ensure the results accurately reflected their perceptions. The data were determined to be saturated when no new subthemes emerged from the ninth interview. 


\section{RESULTS}

\section{Participants}

Two females and seven males participated in this study (Table 1). Four were $S \& C$ coaches, four were physiotherapists, and one was an S\&C coach with a background in physiotherapy. All had five or more years working with athletes and had experience with injured athletes. Participants worked with athletes in a range of sports and levels of competition. This included physiotherapists and S\&C coaches employed as part of a sports team's staff and independent, community-level physiotherapists and S\&C coaches.

\section{Themes}

Thirteen themes relating to the role of the S\&C coach in athlete rehabilitation were identified in four categories (Table 2).

In general, participants perceived that S\&C coaches do not have enough teamwork, involvement, or roles in athlete rehabilitation. They expressed that the role of the S\&C coach in athlete rehabilitation is not concrete. Multiple variables must be considered to avoid barriers and optimise the S\&C coach's role. However, all saw the role of the S\&C coach in athlete rehabilitation as significant and positive.

\section{Current role}

Three main themes relating to the current role of the S\&C coach in athlete rehabilitation were identified from the data: level of involvement, physical roles, and teamwork (Table 2). Participants felt that the S\&C coach's current role, including involvement, physical roles, and teamwork, depends on the factors discussed in the variables theme. The results of this thematic analysis helped build a model for the current role of the S\&C coach in athlete rehabilitation, as seen in Figure 1.

Participants thought that most S\&C coaches currently have minimal involvement in athlete rehabilitation. It seems that physiotherapists perform most of the rehabilitation, and "S\&C [coaches] will pick people up in that grey area ... that exists between where physio finishes and return to play starts" (PT3). S\&C coaches, therefore, mainly work in the end stages of rehabilitation. In lower-level sport settings, "physios will make all the calls around when athletes are ready to [return to sport]" (PT3). However, some highly trained S\&C coaches have greater involvement, working in early rehabilitation. S\&C 4 recalled that, in one setting, the S\&C coach and physiotherapist "team tagged massage, we team tagged injury management" (SC4).

\section{Table 1}

Participant Characteristics

\begin{tabular}{|c|c|c|c|c|c|c|c|c|c|c|c|}
\hline \multirow{2}{*}{ I.D. } & \multirow{2}{*}{ Participant type } & \multirow{2}{*}{$\begin{array}{l}\text { Interview } \\
\text { length (hr) }\end{array}$} & \multirow{2}{*}{ Sex } & \multirow{2}{*}{$\begin{array}{l}\text { Age range } \\
\text { (years) }\end{array}$} & \multicolumn{5}{|c|}{ Level of athletes } & \multirow{2}{*}{$\begin{array}{l}\text { Years working } \\
\text { with athletes }\end{array}$} & \multirow{2}{*}{ Main sport } \\
\hline & & & & & $L$ & $A R$ & PR & AN & PN & & \\
\hline SC1 & S\&C coach & $1: 28: 31$ & M & $21-30$ & $\checkmark$ & $\checkmark$ & & & & 5 & Rugby \\
\hline PT1 & Physiotherapist & $1: 16: 03$ & M & $31-40$ & $\checkmark$ & $\checkmark$ & $\checkmark$ & $\checkmark$ & & 8 & Volleyball \\
\hline PT2 & Physiotherapist & 1:01:09 & M & $41-50$ & $\checkmark$ & & & $\checkmark$ & & 5 & Mixed \\
\hline SC2 & S\&C coach & $1: 31: 54$ & M & $21-30$ & $\checkmark$ & $\checkmark$ & $\checkmark$ & $\checkmark$ & $\checkmark$ & 5 & Kayaking \\
\hline РT3 & Physiotherapist & $1: 28: 17$ & M & $31-40$ & $\checkmark$ & & $\checkmark$ & & $\checkmark$ & 9 & Rugby \\
\hline SC/PT & S\&C coach/physiotherapist & $1: 21: 17$ & M & $31-40$ & & & $\checkmark$ & & $\checkmark$ & 7 & Cricket \\
\hline SC3 & S\&C coach & $1: 10: 26$ & M & $21-30$ & & $\checkmark$ & $\checkmark$ & & $\checkmark$ & 5 & Football \\
\hline PT4 & Physiotherapist & $1: 32: 31$ & $\mathrm{~F}$ & $21-30$ & $\checkmark$ & $\checkmark$ & & & & 5 & Mixed \\
\hline SC4 & S\&C coach & $1: 22: 14$ & $\mathrm{~F}$ & $51-60$ & $\checkmark$ & $\checkmark$ & $\checkmark$ & $\checkmark$ & $\checkmark$ & 40 & Basketball \\
\hline
\end{tabular}

Note. $A N=$ amateur national; $A R=$ amateur regional; $F=$ female; $L=$ local; $M=$ male; $P N=$ professional national; $P R=$ professional regional; $\mathrm{PT}=$ physiotherapist; $\mathrm{SC}=$ strength and conditioning

\section{Table 2}

Categories and Themes

\begin{tabular}{llll}
\hline Current role & Proposed role & Variables & Significance \\
\hline $\begin{array}{l}\text { Teamwork with the } \\
\text { rehabilitation team }\end{array}$ & $\begin{array}{l}\text { Teamwork with the } \\
\text { rehabilitation team }\end{array}$ & Rehabilitation team structure & Positive \\
\hline Level of involvement & Level of involvement & Governance & Negative \\
\hline Physical roles & Physical roles & $\begin{array}{c}\text { Relationships in the } \\
\text { rehabilitation team }\end{array}$ & The athlete \\
\cline { 2 - 3 } & Understanding your own role & &
\end{tabular}


The physical roles of S\&C coaches that participants identified were planning and providing performance training to injured athletes. Again, how much of this S\&C coaches can provide seems to be quite variable. Some S\&C coaches and physiotherapists "work closely ... because every day you're planning and adjusting ... athletes' programmes " (PT3). More often, S\&C coaches are not involved in planning rehabilitation. Some S\&C coaches have found that, without their input, physiotherapist lead rehabilitation programmes that "were good in principle but ... there just didn't seem to be enough resistance to make any change" (SC2). S\&C coaches can help add this resistance and sport specificity, but their involvement in rehabilitation depends on their relationship with the physiotherapist and athlete.

Participant perceptions on teamwork between S\&C coaches and physiotherapists were mixed: "there's been some great examples and some terrible" (SC2). Some had good experiences, working "interchangeably" (SC4) as needed, but it seems that in most cases, "people come to physio and only the lucky few end up with a strength and conditioning coach" (PT4). It was suggested that the best teamwork occurs in high-performance sport and team sport environments such as "High Performance (Sport) New Zealand" (PT2), but community sport S\&C coaches often have minimal or no teamwork with physiotherapists. This is explained in more detail in the variables theme.

\section{Figure 1}

The Perceived Current Role of S\&C Coaches in Athlete Rehabilitation

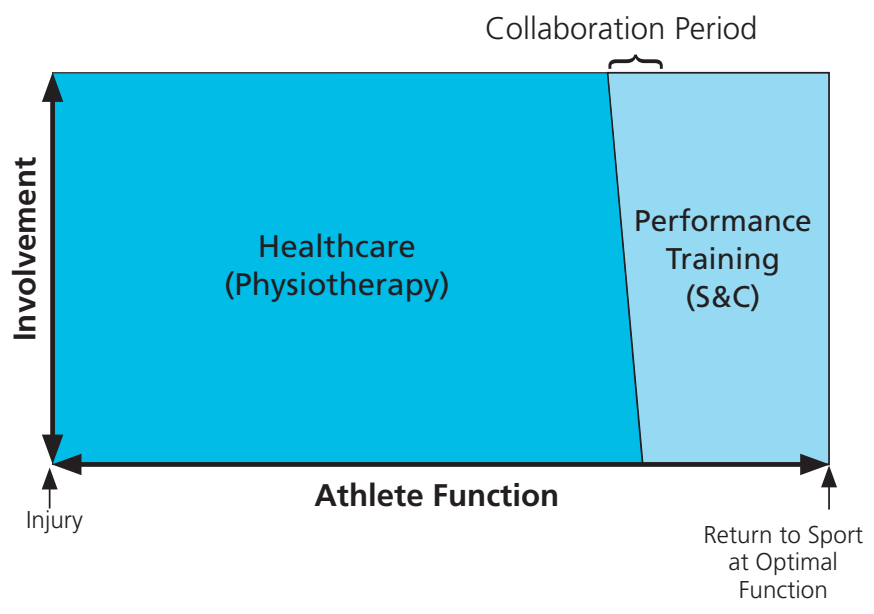

\section{Proposed role}

The proposed role was created based on commonly suggested roles for S\&C coaches. Four main themes relating to the proposed ideal role of the S\&C coach in athlete rehabilitation were identified from the data: 'level of involvement', 'physical roles', 'teamwork', and 'understanding your own role' (Table 2).

Participants felt that the $S \& C$ coach should be involved as soon as the athlete is injured. The S\&C coach's role would be minimal at first, about "90:10 in favour of the physio" (SC2). As the athlete's function improves, the S\&C coach's involvement would increase, and the physio's involvement should decrease. The roles may be shared "50:50 in end-stage rehab" (PT4), and then
S\&C coaches would have a significant role in generic specific and sport-specific development of the athlete ( e.g., "99\% S\&C" [SC2] or "95:5" [SC4]) (Figure 2).

In this proposed role, S\&C coaches' roles could include anything except for making the diagnosis. It was suggested that "the physio ... will examine, re-evaluate, diagnose, and ... manage the pain" (SC2), but S\&C coaches "need to have a voice ... around what the plan looks like going forwards" (SC/PT). In early rehabilitation, S\&C coaches should help the physiotherapist to keep the rehabilitation "angled towards ... performance outcomes" (SC/PT) and allow the athlete to stay conditioned for sport: "ankle surgery, for example ... we can still do stuff with the upper body ... cardiovascular [training]" (PT1). S\&C coaches would have the most roles in performance training near the end of rehabilitation, adding "functionality and ... individuality to the training" (SC4) to prepare the athlete for their sport.

All participants agreed that coordinating the S\&C coach's and physiotherapist's roles requires excellent teamwork skills. They thought the S\&C coach and medical team should regularly communicate and "work collaboratively" (PT2) throughout the athlete's complete rehabilitation (Figure 2 - collaboration period) "to try and achieve a full and sustained return to play" (PT2). They also thought that physiotherapists and S\&C coaches could form a "symbiotic relationship" (PT2) and agreed they are "both required in programmes because [they] add value and ... knowledge that's closely linked" (PT3).

This proposed role should be flexible, and the S\&C coach must understand their role for this to happen. Participants thought "the $[S \& C]$ coach ... has to know his or her limitations and refer on" (PT1). They felt that more experienced S\&C coaches would have greater roles in areas they are skilled in, but ultimately "egos need to be put aside so that the athlete gets the best deal" (SC4).

\section{Figure 2}

The Proposed Role of S\&C Coaches in Athlete Rehabilitation

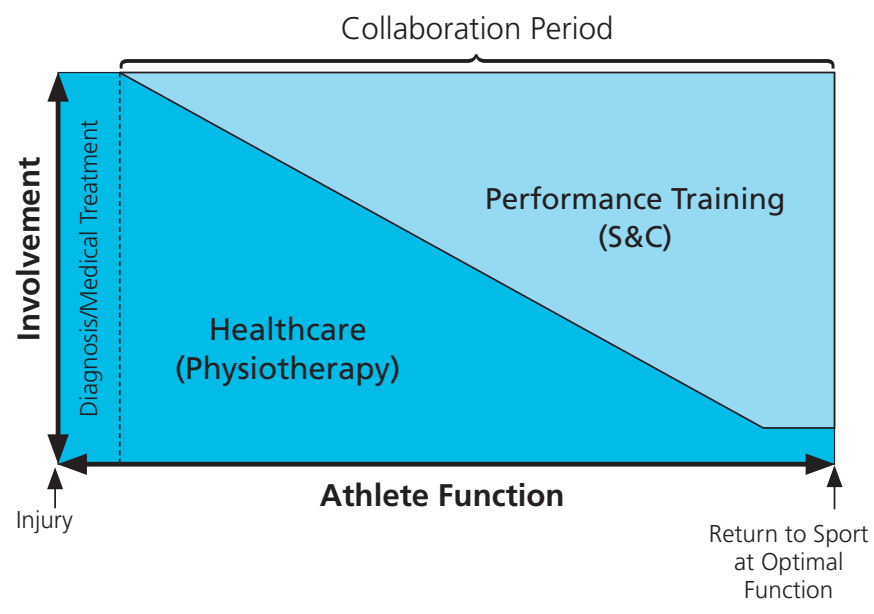

Variables

Participants identified multiple variables that affect the role of the S\&C coach in athlete rehabilitation. These variables were categorised into four main themes: 'rehabilitation team structure', 'relationships in the rehabilitation team', 
'governance', and 'the athlete' (Table 2). These variables may act as barriers to S\&C coaches performing their role or scenarios that require the $S \& C$ coach to adapt their role. Some may lead to a larger role for S\&C coaches (Figure 3), and some lead to a larger role for physiotherapists (Figure 4).

\section{Figure 3}

S\&C Coach Dominant Athlete Rehabilitation

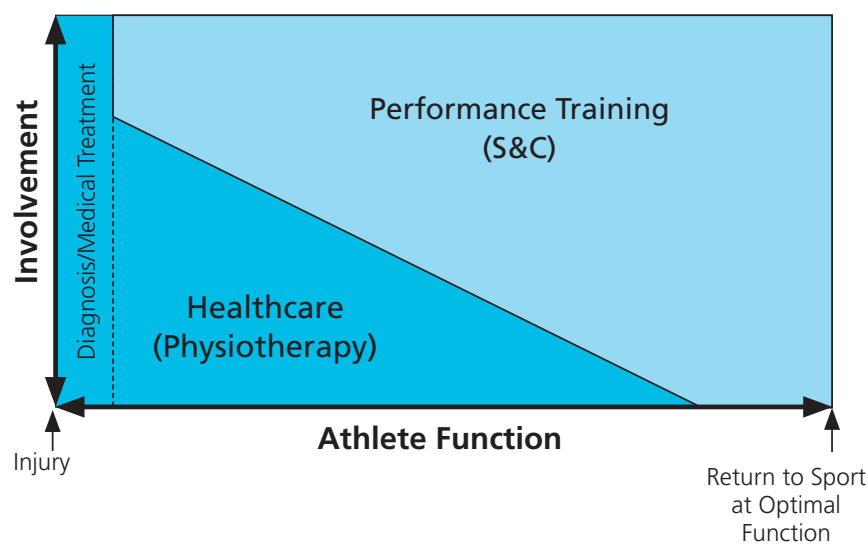

Figure 4

Physiotherapist Dominant Athlete Rehabilitation

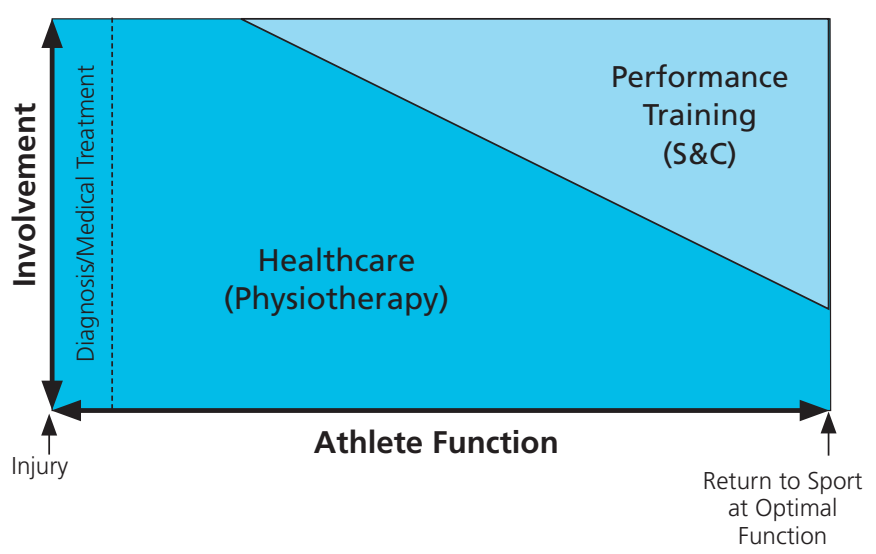

Participants suggested that the organisation of the rehabilitation team and the skills and experience of team members determine how roles are distributed. They thought that the relative experience of the S\&C coach and physiotherapist should affect how involved the S\&C coach is in each section of the rehabilitation. For example, if the $S \& C$ coach is relatively more experienced in rehabilitation than the physiotherapist, then the S\&C should take up more roles earlier (Figure 3) and vice versa (Figure 4). This system ensures that "whoever is leading [rehabilitation] is just whoever is best suited for the job" (SC/PT). In addition, participants thought that S\&C coaches are "more involved ... earlier in an interdisciplinary team ... [and] later in a multidisciplinary team" (PT3).

Participants regularly discussed the relationships and communication the $S \& C$ coach has with the other rehabilitation team members and how this would affect their role. They stressed that if S\&C coaches develop good relationships and communicate with the rehabilitation team, their role increases.
Physiotherapist 2 thought this was because "building the relationship creates trust and ... you know that they'll do a good job".

Some participants suggested that the governing structure, including accreditation and funding of S\&C coaches, may also affect their roles in athlete rehabilitation. They indicated that mandatory accreditation and a governing body would help "strengthen the whole relationship between the two professions" (SC 1) of physiotherapy and S\&C. Physiotherapist 2 felt that referring physiotherapists "want to have some ... level of comfort that, that there's ... standardisation". A governing body could also set up funding structures so S\&C coaches can "make a living out of it ... support themselves ... and have ... career progression ... if it's not sustainable, it won't work".

Most participants agreed that the critical variable is the athlete, as they are the focus for rehabilitation. Ultimately, athletes can choose their healthcare providers, and they may not include the S\&C coach. Therefore, the athlete must understand the role of the S\&C coach to see their value and comply with their programmes. "If the player ... can still get by, and perform oncourt ... doing the bare minimum, they might go 'I can perform, why do I need to do this extra stuff?'" (PT1).

Participants thought "it depends on the level and type of sport as well" (PT1). For example, high-level sports will have more funding and resources to support an S\&C coach in athlete rehabilitation, but "In the amateur side of things, it becomes... much more challenging because ... generally, you don't have a physio or an S\&C" (SC/PT). In addition, elite athletes are more likely to require an $S \& C$ coach to meet their performance needs. For instance, "social basketball ... nobody bothers getting a [S\&C] coach" (PT1).

The athlete's injury must also be considered. Participants thought that the distribution of roles between the physiotherapist and S\&C coach should not change because of the severity and type of injury. They thought both should have proportionately more involvement in an injury that has a long timeframe: "it's similar. It's just on a longer scale" (SC3) (Figure 5).

\section{Figure $\mathbf{5}$}

Perceived Effect of Injury Severity on Involvement in Athlete Rehabilitation

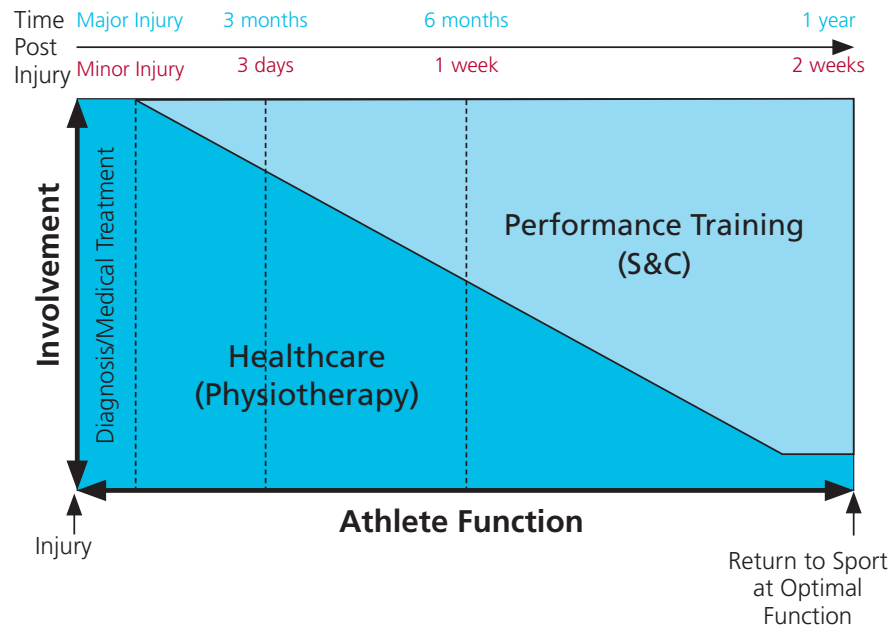




\section{Significance}

Overall, participants felt that the role of the S\&C coach is significant to athlete rehabilitation. Their comments were categorised into two themes: 'S\&C coaches have a positive effect on athlete rehabilitation' and ' $S \& C$ coaches have a negative or no effect on athlete rehabilitation' (Table 2).

Participants noted multiple positive effects of involving S\&C coaches in athlete rehabilitation. They saw the $S \& C$ coach as a valued member of the athlete rehabilitation team. Seven of the nine participants, including all the physiotherapists, thought the $S \& C$ coach was at least as important as the physiotherapist in athlete rehabilitation. They seem to "build a great amount of trust" (SC1) with physiotherapists and often already have "buy-in" (PT1, SC1) from athletes, which helps the rehabilitation team, as it "gets your athletes trusting you" (PT3).

S\&C coaches may be able to provide additional support to physiotherapy. S\&C coaches can see "athletes for a longer period of time than the physio can" (SC1). This may mean they can achieve more within one exercise session. Participants also thought physiotherapists and S\&C coaches could learn from each other if they collaborate and ask questions such as, "Okay, why are we doing this? Can we do it better?" (SC3).

All participants discussed the significance of S\&C coaches' performance mindsets. They thought that having the S\&C coach involved helps "to find your sweet spot" (PT3), balancing health and performance goals. They thought this would lead to better athlete outcomes and improve compliance to rehabilitation "because they feel like they are training in a wellness environment, not a sickness environment, so they actually feel like they're just training" (SC4).

Overall, participants agreed that "athlete outcomes are number one" (PT3) in athlete rehabilitation, and having an S\&C coach involved would lead to better outcomes. Some suggested that athletes would have "shorter time out of the game" (PT3), while others thought that "it may not improve on-time ... but ... they can probably get better outcomes" (PT2). Most thought that performance training and injury reduction go "hand in hand... If you're better prepared, you'll ... perform better, and you're less likely to get injured" (SC3).

However, there were negatives that participants brought up as well. Some thought "there is no problem in the rehabilitation process without an S\&C [coach]" (SC1). Many athletes have good outcomes in return to sport without S\&C coaches. However, the same could be said of any medical professional, and 'good outcomes' are not always the best outcomes. It, therefore, seems essential to consider the context and the athlete's needs before deciding whether an S\&C coach is suitable.

There were some concerns about S\&C coaches and physiotherapists crossing professional boundaries. "S\&C [coaches] try and get involved too early ... when a player is not ready and push them too much ... or vice versa, where the physios don't trust the S\&C [coach]" (SC3). This could make it difficult for athletes to know what information is best for their rehabilitation: "Getting told from one guy 'look, you're not quite ready ... and you've got your S\&C [coach] saying, ' ... I think you're ready' ... The athlete will be thinking ... 'Who do I believe?'" (PT3).

Participants thought that negative scenarios only happened when communication and relationships between S\&C coaches and the rest of the rehabilitation team are poor. If the variables listed in the above section are all considered, they thought that S\&C coaches would positively affect athlete rehabilitation.

\section{DISCUSSION}

To our knowledge, this is the first study that has explored the perceptions of physiotherapists and S\&C coaches on the role of the S\&C coach in athlete rehabilitation. The themes in this study were analysed in four categories. These themes in their respective categories were: current role (teamwork with the rehabilitation team, level of involvement, and physical roles), proposed role (teamwork with the rehabilitation team, level of involvement, and physical roles), variables (rehabilitation team structure, governance, relationships in the rehabilitation team, and the athlete), and significance (positive and negative).

This study adds to emerging literature that attempts to clarify the role of $S \& C$ coaches in athlete rehabilitation. Previous literature provides a general framework (Kraemer et al., 2009; Lorenz et al., 2010; Maestroni et al., 2020; Reiman \& Lorenz, 2011). This study explored the perceptions of S\&C coaches and physiotherapists to clarify how the role is currently performed and how they think it should be performed.

The current role of the S\&C coach was not clearly defined across all participants, but a spectrum of roles could be ascertained. Perceptions on the role of the S\&C coach in athlete rehabilitation were mixed, suggesting that $S \& C$ coaches perform various roles depending on the S\&C coach and the context. The spectrum of roles spans from not involved at all to only involved in performance training during the end stages of rehabilitation to involved throughout the whole rehabilitation process. It seems that most are either not involved or only involved in end-stage rehabilitation, but S\&C coaches with high skill levels or in highly collaborative team environments will have a much more significant role. Most agreed that S\&C coaches who have minimal involvement in athlete rehabilitation should be more involved.

Participants had a much more consistent proposed role for the S\&C coach in athlete rehabilitation. They thought S\&C coaches should have some involvement following a health professional's diagnosis, and their greatest involvement should be in the performance training of injured athletes. The athlete has a greater need for performance training as their function improves. Therefore, participants suggested that the S\&C coach's role should be small at first but increase as athlete function improves and the physiotherapist's role decreases. Therefore, S\&C coaches and physiotherapists would be required to collaborate throughout the whole rehabilitation process, and their teamwork would have to be excellent. In addition, participants agreed that the S\&C coach's role must be flexible and account for contextual and personal variables in the athlete's rehabilitation.

S\&C coaches seem to perform their role in athlete rehabilitation more easily in interdisciplinary teams than multidisciplinary 
teams. However, if multidisciplinary teams communicate well, then the S\&C coach can still perform their role. Many rehabilitation teams are multidisciplinary. Patients are sequentially passed between health professionals with minimal collaboration (Chamberlain-Salaun et al., 2013; Körner, 2010). This seems to be how most S\&C coaches are currently included in rehabilitation teams, especially in community sport settings. Participants thought interdisciplinary teams, which have greater collaboration (Chamberlain-Salaun et al., 2013; Körner, 2010), are preferable for S\&C coaches to perform their role. Participants who worked in interdisciplinary teams were usually involved in high-level sport or team sports on a contract basis. This allows S\&C coaches and physiotherapists to have regular informal and formal, face-to-face communication. Therefore, they can collaborate efficiently in the planning and implementation of rehabilitation: "you've got S\&C [coaches] you work closely with them because every day you're planning and adjusting players' and athletes' programmes" (PT3). Therefore, professionals in community settings (i.e., multidisciplinary teams) will have to be more creative with their communication methods to improve relationships and collaboration. Participants suggested phone calls, text messages, email, video calls, organising face-to-face meetings, or attending gym or physiotherapy sessions.

Once teams are collaborating effectively, it is easier to organically understand and distribute roles to suit each other's strengths (Green \& Johnson, 2015; Rosen et al., 2018; Sims et al., 2015). Participants saw the importance of this and commented that S\&C coaches and physiotherapists need to understand their own roles as well as each other's to ensure that tasks are distributed to "whoever is best suited for the job" (SC/ PT). This must be decided on multiple factors, including their knowledge and practical skills, personality, relationships with the athlete, and rehabilitation team members. The critical variable identified by participants is the athlete. Therefore, the proposed role of S\&C coaches takes a 'patient-centred approach' (Rathert et al., 2013). Athletes must understand and value what S\&C coaches can provide to involve them in their rehabilitation.

Participants identified the current governing structure of S\&C as a barrier to $S \& C$ coaches performing their role in athlete rehabilitation. S\&C does not have a nationally recognised governing body in New Zealand, and they are not obligated to gain qualifications to practice. SC4 described it as "a cowboy industry". Many employers will expect experience or qualifications. However, to health professionals, who are not as well informed, it may be hard to assess an S\&C coach's competence without knowing them personally. This may also explain why S\&C coaches seem to perform their role more easily in interdisciplinary teams. Their education is so variable that many need to develop and understand their role through faceto-face collaboration with health professionals. Ultimately, S\&C coaches who do not have personal relationships with health practitioners will receive fewer referrals and will not develop this role. A governing body may highlight the importance of the $S \& C$ coach's role in athlete rehabilitation, provide more consistent education and competency thresholds, and create funding structures for S\&C coaches. If S\&C coaches cannot get paid for their work in rehabilitation, it will not be sustainable.
Research implications

This is the first qualitative study to assess the role of the S\&C coach in athlete rehabilitation. Although this study provides the perceptions of $S \& C$ coaches and physiotherapists of the role, further research on perceptions of other rehabilitation team members would help clarify the proposed role and their understanding of the role. Most notably of these team members would be the athlete themselves, because, ultimately, the athlete will be the one deciding their rehabilitation pathway.

Furthermore, the proposed role of the S\&C coach identified in this paper could be tested through quantitative research. For example, researchers could develop a randomised controlled trial that compares S\&C coaches working collaboratively in this proposed role versus a control of standard physiotherapy. A study like this could assess rehabilitation time, rehabilitation outcomes, performance outcomes, and injury recurrence with and without the input of S\&C coaches. Future studies should focus on this type of research to assess whether the proposed role of S\&C coaches is effective in athlete rehabilitation.

\section{Strengths and limitations}

The sample size of nine participants interviewed in this study is relatively small but adequate for saturation of homogenous groups (Guest et al., 2006). While a mix of physiotherapists and S\&C coaches may not be considered homogenous, participants were linked through their experience in athlete rehabilitation and agreed on many ideas. In addition, both physiotherapists and S\&C coaches were equally represented in this study. As the ninth interview provided no further subthemes, data saturation was achieved.

A key strength of this paper is that it provides a 'real world' perspective of the role of S\&C coaches in athlete rehabilitation. While this may not capture the views of all physiotherapists and S\&C coaches, it gives insight into the opinions of those who have experience in rehabilitating athletes. Quantitative data does not further support this, but it provides fertile ground for future study and clinical application. Therefore, the proposed role should be tested in research and clinically in athlete rehabilitation teams.

Purposive sampling could be considered a key limitation of this paper. This sampling strategy risks bias of the researcher impacting the selection process, but heterogeneous sampling helped ensure diversity among participants. The participants selected represent a range of ages, experiences, and education and have worked with various sports and competitive levels. The two female and seven male participants correlate well with S\&C coach (Dwyer et al., 2019; Jones et al., 2019) and sport physiotherapy populations (Öhman et al., 2001). Although physiotherapy is female-dominated overall (Physiotherapy Board of New Zealand, 2020; Reid \& Dixon, 2018), men are more likely to be involved in sports physiotherapy (Dahl-Michelsen, 2014; Öhman et al., 2001). Even so, the participants selected were from New Zealand, and their views may not represent physiotherapists and S\&C coaches in other countries where processes and professional roles differ. 


\section{CONCLUSION}

This study found that physiotherapists and S\&C coaches in New Zealand do not think S\&C coaches can perform their role in rehabilitation optimally. These participants believed S\&C coaches should have much more involvement and collaboration with physiotherapists in athlete rehabilitation. However, there are multiple barriers to their role. A key barrier is a lack of role clarity. This study should help to clarify the S\&C coach's role in rehabilitation and help rehabilitation teams understand the variables that affect this role. This may lead to more opportunities for S\&C coaches to work in athlete rehabilitation.

\section{KEY POINTS}

1. Physiotherapists and $S \& C$ coaches proposed that $S \& C$ coaches should provide performance training and a performance context for athlete rehabilitation.

2. Physiotherapists and S\&C coaches suggested that S\&C coaches and health professionals should communicate in early rehabilitation, and S\&C coach involvement should increase with athlete function.

3. S\&C coaches and health professionals should collaborate during athlete rehabilitation to distribute roles that suit the strengths of each professional and the needs of the athlete.

\section{DISCLOSURES}

No funding was obtained for this study. The primary author was a physiotherapist and S\&C coach. This was identified as a potential conflict of interest and was ameliorated by making participants aware of the author's background and crosschecking themes with the other authors. There are no other conflicts of interest that may be perceived to interfere with or bias this study.

\section{PERMISSIONS}

Ethical approval was obtained from the Otago Polytechnic Research Ethics Committee (reference number 840). All participants provided verbal and written informed consent.

\section{ACKNOWLEDGEMENTS}

We gratefully acknowledge the participants for their time and insights into this emerging topic.

\section{ADDRESS FOR CORRESPONDENCE}

Codi Ramsey, Institute of Sport, Exercise \& Health, Otago Polytechnic, Forth Street Campus, Dunedin, New Zealand.

Email: Codi.Ramsey@op.ac.nz

\section{REFERENCES}

Araújo, C. G. S., \& Scharhag, J. (2016). Athlete: A working definition for medical and health sciences research [Editorial]. Scandinavian Journal of Medicine and Science in Sports, 26(1), 4-7. https://doi.org/10.1111/ sms. 12632

Battaglia, M. (2008). Purposive sample. In P. J. Lavrakas (Ed.), Encyclopedia of survey research methods (pp. 645-647). SAGE Publications, Inc. https:// www.doi.org/10.4135/9781412963947.n419

Bedoya, A. A., Miltenberger, M. R., \& Lopez, R. M. (2015). Plyometric training effects on athletic performance in youth soccer athletes: A systematic review. Journal of Strength and Conditioning Research, 29(8), 2351-2360. https://doi.org/10.1519/JSC.0000000000000877
Braun, V., \& Clarke, V. (2006). Using thematic analysis in psychology. Qualitative Research in Psychology, 3(2), 77-101. https://doi. org/10.1191/1478088706qp063oa

Braun, V., \& Clarke, V. (2013). Successful qualitative research: A practical guide for beginners. Sage.

Bull, J. P. (1978). Measures of severity of injury. Injury, 9(3), 184-187. https:// doi.org/10.1016/0020-1383(78)90004-9

Bulley, C., Donaghy, M., Coppoolse, R., Bizzini, M., van Cingel, R., DeCarlo, M., Dekker, L., Grant, M., Meeusen, R., Phillips, N., \& Risberg, M. (2005) Sports physiotherapy competencies and standards. Sports physiotherapy for all project. http://ifspt.org/wp-content/uploads/2014/06/Competencies. pdf

Chamberlain-Salaun, J., Mills, J., \& Usher, K. (2013). Terminology used to describe health care teams: An integrative review of the literature. Journal of Multidisciplinary Healthcare, 6, 65-74. https://doi.org/10.2147/JMDH. S40676

Dahl-Michelsen, T. (2014). Sportiness and masculinities among female and male physiotherapy students. Physiotherapy Theory and Practice, 30(5), 329-337. https://doi.org/10.3109/09593985.2013.876692

Dwyer, D. B., Bellesini, K., Gastin, P., Kremer, P., \& Dawson, A. (2019). The Australian high performance and sport science workforce: A national profile. Journal of Science and Medicine in Sport, 22(2), 227-231. https:// doi.org/10.1016/j.jsams.2018.07.017

Green, B. N., \& Johnson, C. D. (2015). Interprofessional collaboration in research, education, and clinical practice: Working together for a better future. Journal of Chiropractic Education, 29(1), 1-10. https://doi. org/10.7899/jce-14-36

Guest, G., Bunce, A., \& Johnson, L. (2006). How many interviews are enough? An experiment with data saturation and variability. Field Methods, 18(1), 59-82. https://doi.org/10.1177/1525822X05279903

Holloway, I., \& Galvin, K. (2016). Qualitative research in nursing and healthcare (4th ed.). John Wiley \& Sons. https://www.wiley.com/en-us/ Qualitative+Research+in+Nursing+and+Healthcare \%2C+4th+Editionp-9781118874486

Jones, B. W., Humphrey, R. A., Ramsey, C. A., Middlemas, S., \& Spencer, K. (2019). Working conditions of strength and conditioning coaches in New Zealand and the Pacific Islands [Master's thesis, Otago Polytechnic]. Otago Polytechnic. https://www.op.ac.nz/assets/OPRES/SEH-Jones-2019-thesis. pdf

Körner, M. (2010). Interprofessional teamwork in medical rehabilitation: A comparison of multidisciplinary and interdisciplinary team approach. Clinical Rehabilitation, 24(8), 745-755. https://doi. org/10.1177/0269215510367538

Kraemer, W., Denegar, C., \& Flanagan, S. (2009). Recovery from injury in sport: Considerations in the transition from medical care to performance care. Sports Health, 1(5), 392-395. https://doi. org/10.1177/1941738109343156

Lorenz, D. S., Reiman, M. P., \& Walker, J. C. (2010). Periodization: Current review and suggested implementation for athletic rehabilitation. Sports Health, 2(6), 509-518. https://doi.org/10.1177/1941738110375910

Mack, N., Woodsong, C., MacQueen, K. M., Guest, G., \& Namey, E. (2005). Qualitative research methods: A data collector's field guide. Family Health International. https://doi.org/10.2307/3172595

Maestroni, L., Read, P., Bishop, C., \& Turner, A. (2020). Strength and power training in rehabilitation: Underpinning principles and practical strategies to return athletes to high performance. Sports Medicine, 50(2), 239-252. https://doi.org/10.1007/s40279-019-01195-6

Medical Council of New Zealand. (2019). Informed consent: Helping patients make informed decisions about their care. https://www.mcnz.org.nz/ assets/standards/79e1482703/Statement-on-informed-consent.pdf

Meir, R., Diesel, W., \& Archer, E. (2007). Developing a prehabilitation program in a collision sport: A model developed within English premiership rugby union football. Strength and Conditioning Journal, 29(3), 50-62. https:// doi.org/10.1519/00126548-200706000-00008 
Öhman, A., Stenlund, H., \& Dahlgren, L. (2001). Career choice, professional preferences and gender? The case of Swedish physiotherapy students. Advances in Physiotherapy, 3(3), 94-107. https://doi. org/10.1080/140381901750475348

Onwuegbuzie, A. J., \& Leech, N. L. (2007). Sampling designs in qualitative research: Making the sampling process more public. The Qualitative Report, 12(2), 238-254. https://doi.org/10.46743/2160-3715/2007.1636

Physiotherapy Board of New Zealand. (2018). Physiotherapy standards framework 2018. https://www. physioboard.org.nz/sites/default/files/ Physiotherapy-Board-Code-Standards-Thresholds.pdf

Physiotherapy Board of New Zealand. (2020). Annual report 2020. https:// www.physioboard.org.nz/wp-content/uploads/2020/08/Physio-AnnualReport-2020_FINAL.pdf

Rathert, C., Wyrwich, M. D., \& Boren, S. A. (2013). Patient-centered care and outcomes: A systematic review of the literature. Medical Care Research and Review, 70(4), 351-379. https://doi.org/10.1177/1077558712465774

Reid, A., \& Dixon, H. (2018). Making sense of the numbers. Analysis of the physiotherapy workforce. BERL. https://pnz.org.nz/Folder?Action=View File\&Folder_id=1\&File=PNZ Workforce Issues December 2018.pdf

Reiman, M. P., \& Lorenz, D. S. (2011). Integration of strength and conditioning principles into a rehabilitation program. International Journal of Sports Physical Therapy, 6(3), 241-253. https://www.ncbi.nlm.nih.gov/ pmc/articles/PMC3164002/

Rosen, M. A., DiazGranados, D., Dietz, A. S., Benishek, L. E., Thompson, D., Pronovost, P. J., \& Weaver, S. J. (2018). Teamwork in healthcare: Key discoveries enabling safer, high quality care. American Psychologist Journal, 73(4), 433-450. https://doi.org/10.1037/amp0000298
Sims, S., Hewitt, G., \& Harris, R. (2015). Evidence of collaboration, pooling of resources, learning and role blurring in interprofessional healthcare teams: A realist synthesis. Journal of Interprofessional Care, 29(1), 20-25. https:// doi.org/10.3109/13561820.2014.939745

Sommerfield, L. M., Harrison, C. B., Whatman, C. S., \& Maulder, P. S. (2020). Relationship between strength, athletic performance, and movement skill in adolescent girls. Journal of Strength and Conditioning Research, Advance online publication. https://doi.org/10.1519/ jsc.0000000000003512

Tong, A., Sainsbury, P., \& Craig, J. (2007). Consolidated criteria for reporting qualitative research (COREQ): A 32-item checklist for interviews and focus groups. International Journal for Quality in Health Care, 19(6), 349-357. https://doi.org/10.1093/intahc/mzm042

Triplett, N. T., Brown, V., Caulfield, S., Doscher, M., McHenry, P., Statler, T., Wainwright, R., Alejo, B., Gearity, B., Jost, J., Murray, T., Nitka, M. Rubley, M., Williams, C., Plisk, S., Brass, M., Eickhoff-Shemek, J. A., Epley, B., Herbert, D., ... Wathen, D. (2017). NSCA strength and conditioning professional standards and guidelines. Strength and Conditioning Journal, 39(6), 1-24. https://doi.org/10.1519/SSC.0000000000000348

Wong, P.-L., Chaouachi, A., Chamari, K., Dellal, A., \& Wisloff, U. (2010) Effect of preseason concurrent muscular strength and high-intensity interval training in professional soccer players. Journal of Strength and Conditioning Research, 24(3), 653-660. https://doi.org/10.1519/ JSC.0b013e3181aa36a2 


\section{Appendix A}

\section{INTERVIEW PROMPTS}

\section{Introduction}

Introduction

Ask for consent to record We can stop at any time

It is ok not to answer any of the questions

Any identifying information in this interview will be kept anonymous

Introduce myself and a little about my background

Please tell me about your experience with being / strength and conditioning (S\&C) coaches being involved in athlete rehabilitation

Positives? Negatives?

How has your experience differed when you have been / an S\&C involved by comparison to not involved? How would the outcome of athlete rehabilitation change with the inclusion/exclusion of a strength and conditioning coach in the rehab team?

Prompt: Tell me more about... why do you say it would...?

Who do you think have been the most important members of the rehabilitation team in determining athlete return to sport outcomes?

Why? (e.g., minor ankle sprain vs major ankle surgery)

What do you believe should be the role of the $S \& C$ in athlete rehabilitation?

Prompt: Tell me more about...

Significance?

How does this ideal differ to your experience? (perceived ideal vs perceived actual)

Is this role you have described practical today?

What influences the role they may have? Are there any barriers to them performing their role?

What would have to change to achieve the ideal role?

Has the role changed during your time working as an S\&C/physio?

\section{Idea formation}

Tell me about your experiences working in athlete rehabilitation teams.

Can you please discuss the collaboration and communication there has been in these rehab teams?

How do you communicate with S\&Cs?

How often do you communicate with $S \& C s$ ?

How closely do you communicate with $S \& C s$ ?

What did the S\&C have to offer in the team that you have described? / How may the team and outcome have changed if an

S\&C was involved?

Multidisciplinary = usually not working in the same building, most communication is over the phone, email etc.

Interdisciplinary = working closely together and collaborating regularly with face-face communication, often with team meetings.

How did your experience in an interdisciplinary team differ from your experience in a multidisciplinary team?

How does the S\&C's role change between different teams?

How would your perceptions change if S\&C coaches were obligated to gain certification under a nationally recognised

governing body?

Ideas to expand upon

e.g., You mentioned " $x$ ". Can we go a little deeper into this idea?

e.g., Earlier you said " $\mathrm{x}$ ". Why do you think this is? Can you help me understand this a little better?

\section{Idea clarity}

It has been suggested that, in the rehabilitation continuum, physiotherapists and S\&C coaches should work together in 'endstage rehabilitation' and the S\&C coach should then take over to provide performance training before return to sport.

To what extent do you agree or disagree with this? (perceived ideal vs literature ideal)

In your experience, how does this differ from what actually happens in athlete rehabilitation? (Perceived actual vs literature ideal)

Ideas to clarify

e.g., So far, I'm getting the idea that " $x$ ". Can you help me develop this idea?

e.g., You said that " $x$ ". Can you just help make this idea a little clearer for me?

What additional comments you would like to make with regards to this study? 